\title{
An Aspermia Rat Mutant (as/as) with Spermatogenic Failure at Meiosis
}

\author{
Hiroshi IKADAI, Junko NOGUCHI, Midori YOSHIDA, and Tomonori IMAMICHI \\ The Imamichi Institute for Animal Reproduction, 1103 Fukaya, Dejima-mura, Niihari-gun, Ibaraki 300-01, Japan
}

(Received 25 February 1992/Accepted 30 April 1992)

ABSTRACT. A newly identified aspermia rat mutant was investigated on testicular histology and mode of inheritance of the defect. Average testis weight of mutants was about one-third of that of phenotypically normal males. Spermatogenesis was interrupted at meiosis. Pachytene spermatocytes significantly decreased in number. Secondary spermatocytes and few round spermatids were seen, but no elongated spermatids and sperms were observed. A large basophilic inclusion-like body existed in the cytoplasm of late pachytene spermatocytes. Genetic analysis revealed an autosomal recessive transmission of the defect. Aspermia $(A s)$ was designated for the locus.-KEY wORDS: aspermia, meiosis, mutant, rat.

Spermatogenesis is a complex process including mitosis, meiosis, and spermiogenesis sustained by hypothalamus-pituitary-testicular axis and harmonized local interactions of spermatogonia, Sertoli cells, and Leydig cells [15, 22]. Mutant models blocked at specific stages of the process can provide useful tools to elucidate genetic mechanisms regulating spermatogenesis.

We have recently identified an aspermia rat mutant. The mutant manifests the disruption of spermatogenesis at early meiosis, associating with a large inclusion-like body in the cytoplasm of late pachytene spermatocytes. Secondary spermatocytes and few round spermatids were observed, but no elongated spermatids and sperms were seen. The defect was detected exclusively in testes of the mutant, whereas sibling females were fertile. Meiotic failure with an inclusion-like body in pachytene spermatocytes has not been reported in rodents. This paper describes the testicular histology and mode of inheritance of the disorder.

\section{MATERIALS AND METHODS}

Animals: Rats with bilateral small testes were detected in 1986 in an inbred strain (TT line) having been maintained in the Institute. Since the rats were infertile, phenotypically normal male litters were mated with sibling females and succesive inbreedings within litter mates of the mutant have been made. Animals were kept under a conventional condition and were fed a commercial diet (EM; Oriental Yeast, Co., Ltd., Tokyo) with tap water $a d$ libitum.
Morphological observations: Groups of 5 mutants and phenotypically normal male litters at 25 weeks of age were weighed and sacrificed by decapitation. Testes, epididymides, seminal vesicles, ventral prostate, preputial glands, adrenal glands, pituitary gland, and thyroid glands were removed and weighed immediately. Testes were fixed in Bouin's solution, dehydrated in ethanol, and embedded in paraffin wax. Middle portion of testes was circularly sectioned at $6 \mu \mathrm{m}$, and stained with haematoxylin and eosin for microscopic observation. Elements of germinal epithelium were quantitatively analyzed in randomly selected 4 testes in each group. Diameter of seminiferous tubules, and numbers of Sertoli cells, spermatogonia, early spermatocytes (preleptotene to zygotene) and pachytene spermatocytes were estimated in 36 tubules under a microscope. Stages of seminiferous epithelial cycle of each tubule were determined according to Perey et al. [19] and classified into two groups, stages XIV and I-VI, and stages VII-XIII (18 tubules respectively). Values were averaged and compared between the mutant and phenotypically normal male litters.

Genetic analysis: Since mutants were sterile, sires and dams that produced mutants, designated as carriers, were used for genetic analysis. Carriers in the line were out-crossed with rats in an unrelated line (IS line). Incidence of the mutant defined by small testes was observed in the F1, F2, and backcross generations. In the $\mathrm{F} 2$ and backcross generations, litters produced by carrier F1 males and females were used for statistical analysis. 


\section{RESULTS}

Gross anatomy of the male reproductive tract revealed no abnormality in the mutant. The average body weight of mutants did not differ from that of phenotypically normal litters (Table 1). Weights of testes and epididymides were about one-third and two-thirds of those of phenotypically normals, respectively. The average weights of seminal vesicles, ventral prostate, preputial glands, pituitary gland, and thyroid glands did not differ from those of phenotypically normal rats.

In testes of mutants, diameter of seminiferous tubules decreased (Fig. 1b). Spermatogenesis was interrupted at meiosis. Nearly all seminiferous tubules contained germ cells up to pachytene sprermatocytes. First meiotic divisions were seen. Secondary spermatocytes, most of which stopped their division, existed in tubules at stages XIV and I-VI (Fig. 1d). Multinucleated giant cells were frequently seen in the tubules. Multinucleated giant cells were frequently seen in the tubules. Few round spermatids were recognized, but no elongated spermatids and sperms were seen. A large basophilic inclusionlike body, which was not seen in testes of normal rats, occurred in the cytoplasm of pachytene sper-

Table 1. Body and organ weights

\begin{tabular}{lcr}
\hline & Phenotypically normal & \multicolumn{1}{c}{ Mutant } \\
\hline Body weight (g) & $491.6 \pm 21.4$ & $456.3 \pm 42.5$ \\
Testes (mg) & $3009.6 \pm 89.1$ & $971.8 \pm 38.9^{*}$ \\
Epididymides (mg) & $1603.4 \pm 102.5$ & $1192.3 \pm 77.5^{*}$ \\
Ventral prostate (mg) & $643.0 \pm 86.6$ & $538.5 \pm 46.1$ \\
Preputial glands (mg) & $272.4 \pm 14.3$ & $267.5 \pm 13.1$ \\
Seminal vesicles (mg) & $1644.0 \pm 141.3$ & $1515.3 \pm 65.9$ \\
Pituitary gland (mg) & $10.4 \pm 0.8$ & $10.5 \pm 1.1$ \\
Adrenal glands (mg) & $63.6 \pm 10.2$ & $64.9 \pm 1.3$ \\
Thyroid glands (mg) & $28.9 \pm 4.5$ & $28.0 \pm 2.3$ \\
\hline
\end{tabular}

Each value indicates mean \pm SD. *; $\mathrm{P}<0.05$.

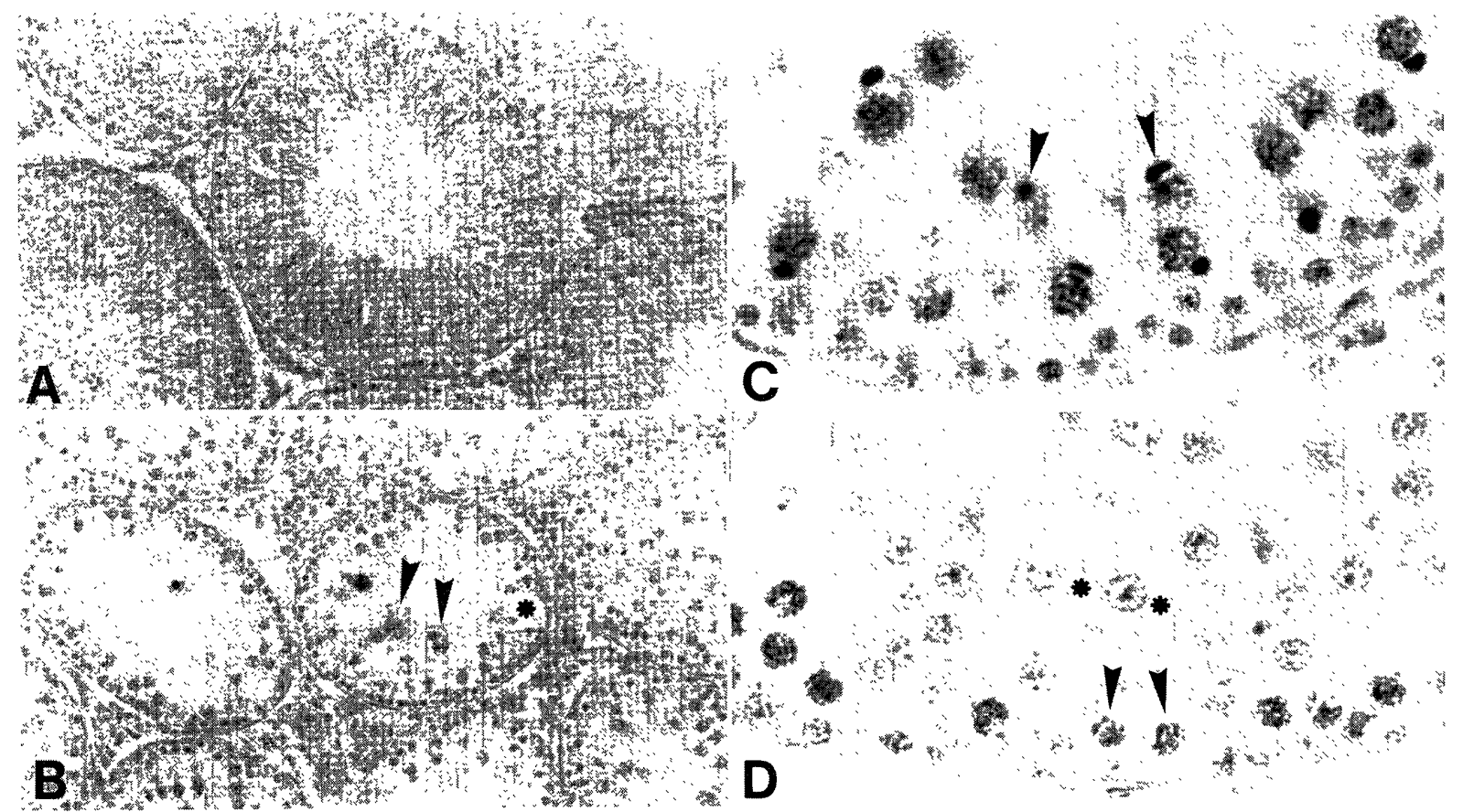

Fig. 1. Cross-sections of the testes of phenotypically normal (a) and mutant (b-d) rats. Active spermatogenesis is seen in phenotypically normal rats (a). In the mutant testes, seminiferous tubules decreased in diameter and contained multinucleated giant cells (arrowheads) and large vacuoles (asterisk). No elongated spermatids and sperms are seen (b). A large inclusion-like body (arrowheads) is seen in the cytoplasm of late pachytene spermatocytes (c). Secondary spermatocytes (asterisks) cease cell division (d). No inclusion-like body occurs in early pachytene spermatocytes (arrowheads). Magnification, $\times 150$ in a and $b$, $\times 600$ in $c$ and $d$. 
matocytes (Fig. 1c). The inclusion-like body was not observed in early pachytene spermatocytes (at stages I-VI), appeared abruptly in late pachytene spermatocytes (at stages VII-XIII), and disappeared in secondary spermatocytes. Sertoli cells showed no abnormality in their nuclear shape and location. Large vacuoles were occasionally seen in the tubules. Leydig cells in the interstitium seemed to be hyperplastic. Quantitative estimation in numbers of Sertoli cells, spermatogonia, and early spermatocytes revealed no significant difference between mutants and phenotypically normal litters (Table 2). The number of pachytene spermatocytes was, however, significantly lower than that of phenotypically normal rats.

The defect was inherited as an autosomal recessive. Incidence of mutants in the line was $43 \%$ (43 out of 100) in the sibling males of 22 litters that produced mutants. This value indicates two possibilities in mode of inheritance of the defect; X chromosome transmission and autosomal recessive transmission in which appearance of defect is limited to males. To ascertain which is the case, phenotypically normal carrier males and females in the line were out-crossed reciprocally with an unrelated line. In the $\mathrm{F} 1$ generation derived from carrier males and females (crosses a-1 and b-1 in Table 3), the mutant did not appear. This finding excludes the possibility of $\mathrm{X}$ chromosome transmission of the defect. When the defect is controlled by an autosomal recessive locus, carrier males are heterozygous for the locus and carrier females include heterozygotes and recessive homozygotes. The F1 rats include heterozygotes and dominant homozygotes in this case. Therefore, incidences of the mutant in F2 and backcross generations were analysed in offspring from matings between proven $\mathrm{F} 1$ carriers and matings of proven carrier males in the line with proven carrier F1 females, respectively. The mutant appeared in the F2 generations derived from carrier males and females in the parental line (crosses a-2 and b-2) and in the backcross generation derived from parental carrier males (cross a-3). The incidence of the mutant was consistent with the expected values for an autosomal recessive transmission.

\section{DISCUSSION}

The mutant was characterized by spermatogenic failure during meiosis, associating with an inclusionlike body in the cytoplasm of late pachytene spermatocytes. Secondary spermatocytes were seen, but most of them stopped their cell division. Few round spermatids but no elongated spermatids and sperms were seen. The defect was limited to the male gonad, whereas sibling females were fertile. We designated the locus responsible for the defect

Table 2. Germinal elements of the mutant

\begin{tabular}{lcc}
\hline & Phenotypically normal & Mutant \\
\hline Diameter of seminiferous tubules $(\mu \mathrm{m})$ & $251 \pm 22$ & $180 \pm 28^{*}$ \\
No. of Sertoli cells & $17.1 \pm 4.0$ & $18.9 \pm 4.3$ \\
No. of type A spermatogonia & $2.1 \pm 1.1$ & $2.3 \pm 1.6$ \\
No. of intermediate to & $7.0 \pm 5.8$ & $9.1 \pm 8.0$ \\
type B spermatogonia & $45.9 \pm 10.9$ & $43.1 \pm 11.7$ \\
No. of early spermatocytes & $52.7 \pm 5.5$ & $37.5 \pm 6.7^{*}$ \\
No. of early pachytene spermatocytes & $67.6 \pm 9.0$ & $34.9 \pm 9.9^{*}$ \\
No. of late pachytene spermatocytes &
\end{tabular}

Each value indicates mean \pm SD. $* ; P<0.05$.

Table 3. Segregation of aspermia males in offspring from crosses with an unrelated (IS) line

\begin{tabular}{|c|c|c|c|c|c|c|}
\hline \multirow[b]{3}{*}{$(\mathrm{A}-1)$} & \multirow[b]{2}{*}{ Cross } & \multicolumn{2}{|c|}{ Observed } & \multicolumn{3}{|c|}{ Expected for single recessive } \\
\hline & & \multicolumn{2}{|c|}{ Aspermia/Males $(\%)$} & \multicolumn{2}{|c|}{ Aspermia/Males $(\%)$} & \multirow{2}{*}{$\frac{\chi^{2}}{0}$} \\
\hline & IS females $\mathrm{x}$ carrier males & $0 / 7$ & $(0)$ & $0 / 7$ & 0) & \\
\hline$(\mathrm{A}-2)$ & Carrier $\mathrm{F} 1$ females $\mathrm{x}$ Carrier $\mathrm{F} 1$ males & $12 / 52$ & $(23.1)$ & $13 / 52$ & $(25.0)$ & 0.103 \\
\hline$(\mathrm{A}-3)$ & Carrier F1 females $\mathrm{x}$ Carrier males & $9 / 37$ & (24.3) & $9.3 / 37$ & $(25.0)$ & 0.009 \\
\hline (B-1) & Carrier females $\mathrm{x}$ IS males & $0 / 8$ & & $0 / 8$ & $(0)$ & 0 \\
\hline$(B-2)$ & Carrier $\mathrm{F} 1$ females $\mathrm{x}$ Carrier $\mathrm{F} 1$ males & $14 / 55$ & $(25.5)$ & $13.8 / 55$ & $(25.0)$ & 0.007 \\
\hline
\end{tabular}

Crosses A-1-3 derived from carrier males in the line and crosses B-1 \& 2 from carrier females. 
as $A s$ representing aspermia.

The As locus is unique in that the effect is limited to the male gonad and the meiotic disorder is associated with an inclusion-like body in pachytene spermatocytes. Large numbers of mutant models representing spermatogenic failure have been described in mice $[2,6]$ and rats $[8,14-18,24]$. However, there are only two cases for meiotic disorder, $S k s$ in mice and $G r c$ in rats. The $S k s$ locus exerts pleiotropic effects as vertebral fusion, disruption of meiosis in spermatogenesis, and sterility in females by unknown cause [8]. The Grc loci cause meiotic disruption in males and decreased fertility in females closely linked with depressed body growth and major histocompatibility complex [4, 5, 21].

Histochemical and electron microscopical observations on the As mutant testes [1] revealed that the inclusion-like body was composed of degenerating ribosomes including a large amount of ribonucleic acid. Ultrastructure of spermatogonia and early spermatocytes was normal and tight junctions between Sertoli cells were conserved. Noguchi et al. [17] investigated testicular histology and plasma $\mathrm{FSH}, \mathrm{LH}$, and testosterone levels of mutants from weaning to adult and revealed that the defect appears from the first cycle of spermatogenesis at weaning when hormone levels did not differ from those of phenotypically normal litters at corresponding age. Thereafter, FSH and LH levels increased significantly and testosterone level decreased slightly. Intra-testicular administration of testosterone did not repair the spermatogenesis in the mutant. These data exclude hypopituitaryhypogonadism from the cause. The defect in intratesticular elements, spermatocytes per se or its interactions with Sertoli cells, may be attributed to the pathogenesis. During meiosis of spermatogenesis, temporally regulated active gene expression and protein synthesis occur in both spermatocytes and Sertoli cells $[3,18,20,23,25]$. Further investigations such as an analysis of aggregation chimera of mutants and normal rats [16] are needed to define the primary defect.

In summary, we identified an aspermia rat mutant with meiotic failure transmitted by an autosomal recessive locus $(A s)$. The meiotic failure in the mutant is unique in that a large inclusion-like body occurs in the cytoplasm of late pachytene spermatocytes. The mutant will provide a useful model to elucidate the genetic mechanism controlling meiosis of spermatogenesis.
ACKNOWLEDGEMENT. We thank Dr. Y. Hayashi of Veterinary Medical Science, The University of Tokyo, for his kind advice for the study.

REFERENCES

1. Atagi, Y., Ikadai, H., Kurohmaru, M., and Hayashi, Y. 1990. Histological observation of the testicular defect in As mutant. 110th Ann. Meet. Jpn. Vet. Soc. (Abst. Japanese).

2. Chubb, C. 1989. Genetically defined mouse models of male infertility. J. Androl. 10: 77-88.

3. Djakiew, D. and Dym, M. 1988. Pachytene spermatocyte protein influence Sertoli cell function. Biol. Reprod. 39: 1193-1205.

4. Gill III, T. J. and Kunz, H. W. 1979. Gene complex controlling growth and fertility linked to the major histocompatibility complex in the rat. Am. J. Pathol. 96: 185-206.

5. Gill III, T. J., Siew, S., and Kunz, H. W. 1983. Major histocompatibility complex-linked genes affecting development. J. Exp. Zool. 228: 325-345.

6. Handel, M. A. 1987. Genetic control of spermatogenesis in mice. pp. 1-62. In: Spermatogenesis: Genetic Aspects (Henning, W. ed.), Springer-Verlag, Berlin.

7. Handel, M. A., Lane, P. W., Schroeder, A. C., and Davisson, M. T. 1988. New mutation causing sterility in the mouse. Gamate Res. 21: 409-423.

8. Heindel, J. J., Berkowitz, A. S., Grotjan, H. E., Herbert, D. C., Klemckes, H. G., and Bartke, A. 1988. Pituitary and testicular function in the restricted $\left(\mathrm{H}^{\mathrm{re}}\right)$ rat. Int. J. Androl. 11: $313-326$.

9. Ikadai, H., Ajisawa, C., Taya, K., and Imamichi, T. 1988. Suprainguinal ectopic scrota of TS inbred rats. J. Reprod. Fertil. 84: 701-707.

10. Ikadai, H., Ajisawa, C., Tsujimura, S., Watanabe, G., Taya, K., and Imamichi, T. 1988. A new pseudohermaphrodite rat mutant with androgen deficiency. J. Reprod. Fertil. 84: 303-312.

11. Ikadai, H., Fujita, H., Ajisawa, C., and Imamichi, T. 1987. Sperm retention cysts in the efferent duct and testicular atrophy of TE inbred rats. J. Reprod. Fertil. 81: 635-641.

12. Ikadai, H., Sakuma, Y., Suzuki, K., and Imamichi, T. 1985. Congenital abnormalities of the male genital organs in the newly established TW rat strain. Cong. Anom. 25: 65-71.

13. Kamtchouing, P., Hochereau de Reviers, M. T., Perreau, C., Papadopoulos, V., Drosdowsky, M. A., and Carreau, S. 1991. Age-related changes in the function of the pituitary-gonadal axis in a sterile male rat mutant (hd/hd). Biol. Reprod. 45: 11-19.

14. Kaneda, M., Hojo, H., Aoyama, H., Teramoto, S., and Shirasu, Y. 1990. Male infertility in the hereditary polydactyly (PD) rat. Lab. Anim. Sci. 40: 379-383.

15. Maddock, S., Parvinen, M., Soder, O., Punonen, J., and Pollanen, P. 1990. Regulation of the testis. J. Reprod. Immunol. 18: 33-50.

16. Nakayama, H., Kuroda, H., Onoue, H., Fujita, J., Nishimune, Y., Matsumoto, K., Nagano, T., Suzuki, F., and Kitamura, Y. 1988. Studies of $\mathrm{S} 1 / \mathrm{S} 1^{\mathrm{d}}$ mouse aggregation chimeras II. Effect of the steel locus on spermatogenesis. Development 102: 117-126.

17. Noguchi, J., Yoshida, M., Ikadai, H., Imamichi, T., Watanabe, G., and Taya, K. 1988. A new rat mutant with hereditary aspermia: Age related changes in blood concen- 
trations of $\mathrm{FSH}, \mathrm{LH}$, and testosterone and testicular morphology. 8th Ann. Meet. Jpn. Androl. Soc. (Abst. Japanese).

18. Paulssen, R. H., Paulssen, E. J., Gordeladze, J. O. Hansson, V., and Haugen, T. B. 1991. Cell-specific expression of guanine nucleotide-binding proteins in rat testicular cells. Biol. Reprod. 45: 566-571.

19. Perey, B., Clermont, Y., and Leblond, C. P. 1961. The wave of the seminiferous epithelium in the rat. Am. J. Anat. 108: $47-77$.

20. Rivarola, M. A., Sanchez, P., and Saez, J. M. 1985. Stimulation of ribonucleic acid and deoxyribonucleic acid synthesis in spermatogenic cells by their coculture with Sertoli cells. Endocrinology 117: 1796-1802.

21. Siew, S., Gill III, T. J., and Kunz, H. W. 1986. Ultrastructural investigation of the testicular defect in rats carrying MHC-linked genes affecting development. Am. J. Pathol. 123: 318-333.

22. Skinner, M. 1987. Cell-cell interactions in the testis. Ann. New York Acad. Sci. 153: 158-171.

23. Stern, L., Gold, B., and Hecht, N. B. 1983. Gene expression during mammalian spermatogenesis. I. Evidence for stage specific synthesis of polypeptides in vitro. Biol. Reprod. 28: 483-496.

24. Suzuki, K., Hakamata, Y., Hamada, A., Kikukawa, K., Wada, M. Y., and Imamichi, T. 1988. Male hypogonadism as a candidate of deficiency of postnatal testicular growth or differentiating factor(s): a new autosomal recessive mutation in the rat. J. Hered. 79: 54-58.

25. Thomas, K. H., Wilkie, T. M., Tomashefsky, P., Bellve, A. R., and Simon, M. I. 1989. Differential gene expression during mouse spermatogenesis. Biol. Reprod. 41: 729-739. 